\title{
Estimation of lung volume in infants by echo planar imaging and total body plethysmography
}

B Chapman, C O'Callaghan, R Coxon, P Glover, G Jaroszkiewicz, A Howseman, P Mansfield, P Small, A D Milner, R E Coupland

\begin{abstract}
Echo planar imaging (an extremely fast method of magnetic resonance imaging) was used to measure lung volume in a group of nine infants, all of whom had had respiratory problems. The mean echo planar imaging estimate of total lung volume was $44 \pm 9 \mathrm{ml} / \mathrm{kg}$. In each case the right lung was larger than the left (ratio 52.8:47.2\%). The mean thoracic gas volume was $36 \pm 8 \mathrm{ml} / \mathrm{kg}$. The entire sequence of images of the thorax (about 400 ) takes five minutes to complete, infants require no sedation, and there are no side effects.
\end{abstract}

Echo planar imaging is a form of nuclear magnetic resonance imaging that gives short image acquisition times and so permits a sequence of images to be obtained rapidly. Each image is displayed in transection as it is acquired in real time. ${ }^{1-3}$

We have used echo planar imaging to study the thoraxes of nine infants aged between 1 and 9 months, all of whom had had respiratory problems. The measurements were produced on our home built imaging machine operating at a field strength of 0.1 Tesla $(T)$ which corresponds to an operating radio frequency of $4 \cdot 0$ $\mathrm{MHz}$ for protons.

We have compared the results of echo planar imaging for total and individual lung volumes with mean thoracic gas volume measurements. Measurement of thoracic gas volume in infancy by total body plethysmography after bronchiolitis has, however, recently been questioned by Godfrey et $a l .{ }^{4}$ The work described here is an extension of an earlier pilot study. ${ }^{5}$ Nottingham, Physics

B Chapman

R Coxon

$P$ Glover

G Jaroszkiewicz

A Howseman

P Mansfield

Department of Human Morphology

R E Coupland

Department of

Child Health

C O`Callaghan

A D Milner

Department of

Radiology

P Small

Correspondence to:

Professor P Mansfield,

Department of Physics,

University of Nottingham

University Park

Nottingham NG7 2RD.

Accepted 7 August 1989

Patients and methods

Nine infants with recurrent attacks of wheezing were studied (table 1). Cases 8 and 9 had mild wheezes on auscultation; the other patients were clinically well when studied. Cases $2,5,7$, and 8 were studied immediately before discharge from hospital after their wheezing had improved. Measurements of lung volume by plethysmography and by echo planar imaging were made on the same day in cases 4-9 and within two days of each other in cases 2 and 3. Case 9 was studied at 1 and 3 months of age. Case 1 did not have the thoracic gas volume measured.

Infants were sedated with chloral hydrate $(120 \mathrm{mg} / \mathrm{kg}$ ) to allow measurement of thoracic gas volume by total body plethysmography. ${ }^{6-9}$ The total body plethysmograph had a capacity
Table 1 Details of patients studied

\begin{tabular}{lcl}
\hline Case No & Age (months) & $\begin{array}{l}\text { History of } \\
\text { bronchiolitis }\end{array}$ \\
\hline 1 & 8 & Yes \\
2 & 4 & Yes \\
3 & 9 & Yes \\
4 & 8 & No \\
$5^{*}$ & 6 & Yes \\
6 & 6 & No \\
7 & 10 & Yes \\
8 & 10 & Yes \\
9 (at 1 month old) & 2 & No \\
9 (at 3 months old) & 4 & No \\
\hline
\end{tabular}

${ }^{*}$ Case No 5 was the only girl studied.

of 2601 and a servocontrolled heating system to maintain the face mask, shutter system, and rebreathing bag at $36^{\circ} \mathrm{C}$. Thoracic gas volume was measured after inspiration, with subtraction of the tidal volume after calculation. Each child was nursed supine and a latex face mask was applied; this was smeared with petroleum jelly to help secure an airtight seal. The dead space of the mask was $55 \mathrm{ml}$ for patients $1-8$, but a $28 \mathrm{ml}$ mask was used for patient 9 . There was a bias flow of air to the face mask of 51 / minute. Signals were relayed to the axes of a cathode ray oscilloscope, readings were taken by the same observer, and calculations made by standard techniques. From five to eight breaths were analysed in each case.

Infants required no sedation for echo planar imaging studies. The echo planar imaging technique is an extension of nuclear magnetic resonance imaging and the details of its develop-
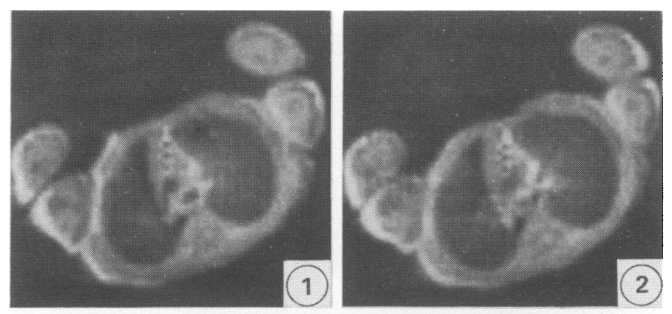

Four contiguous echo planar transectional images through the mediastinum of an infant. The patient's left side is on the left. 
Table 2 Comparison of measured thoracic gas volume by total body plethysmography with total lung volume measurement by echo planar imaging. Also shown is airways resistance

\begin{tabular}{|c|c|c|c|c|c|}
\hline \multirow[t]{2}{*}{ Case No } & \multirow{2}{*}{$\begin{array}{l}\text { Thoracic gas volume } \\
(\mathrm{ml} / \mathrm{kg})\end{array}$} & \multirow{2}{*}{$\begin{array}{l}\text { Airways resistance } \\
\left(\mathrm{cm} \mathrm{H}_{2} \mathrm{O} / \mathrm{ll} / \mathrm{s}\right)\end{array}$} & \multicolumn{3}{|c|}{ Lung volume measured by echo planar imaging } \\
\hline & & & $\begin{array}{l}\text { Total volume } \\
(\mathrm{ml} / \mathrm{kg})\end{array}$ & $\begin{array}{l}\text { Left lung } \\
(m l)\end{array}$ & $\begin{array}{l}\text { Right lung } \\
(\mathrm{ml})\end{array}$ \\
\hline $\begin{array}{l}1 \\
2 \\
3 \\
4 \\
5 \\
6 \\
7 \\
8 \\
9 \text { (at } 1 \text { month old) } \\
9 \text { (at } 3 \text { months old) }\end{array}$ & $\begin{array}{l}\text { Not measured } \\
29 \\
37 \\
37 \\
34 \\
34 \\
60 \\
27 \\
85 \\
70\end{array}$ & $\begin{array}{l}\text { Not measured } \\
60 \\
27 \\
21 \cdot 7 \\
33 \\
19 \\
60 \\
45 \\
31 \cdot 4 \\
55\end{array}$ & $\begin{array}{l}29 \\
50 \\
45 \\
43 \\
36 \\
38 \\
69 \\
41 \\
58 \\
55\end{array}$ & $\begin{array}{r}50 \\
200 \\
110 \\
120 \\
136 \\
159 \\
154 \\
110 \\
119 \\
156\end{array}$ & $\begin{array}{r}54 \\
161 \\
113 \\
195 \\
145 \\
185 \\
155 \\
138 \\
120 \\
205\end{array}$ \\
\hline
\end{tabular}

ment and medical use may be found elsewhere. ${ }^{1-3}$

The procedure requires no gating, because each image is a snapshot acquired within 32 to $64 \mathrm{~ms}$. It is therefore comparatively free of motional artefact from either cardiac or respiratory movement. Each transectional image is $6 \mathrm{~mm}$ thick. A $64 \times 64$ pixel display was used resulting in a true resolution within each slice of $3 \mathrm{~mm}$. Consecutive images are acquired during the cardiac cycle with the first image of each sequence triggered by the QRS complex of the electrocardiogram.

A Winchester quart of known transectional area was used as the standard. The area obtained from this image was measured by planimetry and compared with the known area. A conversion factor was determined and used to convert image screen measurements of lung area to actual size. The same standard was repeated before each study.

The accuracy of area measurement had two components: an inherent error $\left(\varepsilon_{\mathrm{i}}\right)$, which is related to the pixel signal:noise ratio $(R)$ and calculated by $100 /(\mathrm{R} \sqrt{\mathrm{N}}) \%$, where $\mathrm{N}$ is the number of pixels scanned in the area of interest, and an observer error $\left(\varepsilon_{\mathrm{o}}\right)$, which arises from errors in delineating the area of interest and reproducibility. The inherent error is usually around $1 \%$, whereas the observer error is about $10 \%$.

The initial transectional image was obtained at the apex of the lung and at $6 \mathrm{~mm}$ steps towards the base until lung was no longer seen. Numbers of slices ranged from 10-16, depending on the patient. The area of the lung at each stage was measured by planimetry, converted to actual area, and multiplied by the stage thickness to give total and individual estimates of lung volume. Each transectional image measured was a compilation of 16 snapshots taken in rapid succession (figure), so the lung volumes calculated tend to reflect volume in the middle of a tidal breath. All readings were made by the same observer.

This study was approved by the Nottingham ethics committee. Written parental consent was obtained for the observations.

\section{Results}

None of the infants required sedation for echo planar imaging studies, each of which took less than five minutes to carry out.

The measurements of thoracic gas volume and airways resistance, and measurements of individual and total lung volume using echo planar imaging, are shown in table 2 .

The mean thoracic gas volume was $36 \pm 8$ $\mathrm{ml} / \mathrm{kg}$. The estimate of total lung volume by echo planar imaging was $44 \pm 9 \mathrm{ml} / \mathrm{kg}$.

Taking the group as a whole, $47 \cdot 2 \%$ of the total lung volume was in the left lung and $52 \cdot 8 \%$ was in the right lung according to the echo planar imaging. The coefficient of variation for intrasubject measurement of thoracic gas volume was $4 \cdot 1 \%$.

\section{Discussion}

Measurement of thoracic gas volume in infants by total body plethysmography requires sedation and can be a lengthy procedure. In addition, measurement of thoracic gas volume when airways are closed, ${ }^{5}$ and measurement in wheezy infants who have had bronchiolitis, has been questioned. ${ }^{4}$ The use of an imaging technique to calculate total, and-for the first timeindividual, lung volumes in this age group is appealing. Magnetic resonance imaging has no known hazards and studies of the thoraxes of infants using echo planar imaging can be completed within five minutes with no need for sedation.

The plethysmographic measurement and the echo planar imaging estimates differ. Measurements of lung volume obtained by echo planar imaging include volume taken up by lung tissue, hence they should be greater than measurements of thoracic gas volume. In addition measurements of thoracic gas volume were made after inspiration, with subtraction of the tidal volume after calculation, but echo planar imaging measurements were made at what we consider to be mid tidal volume. Thus, in addition to lung tissue volume, they may be expected to be half a tidal volume greater than thoracic gas volume. Using echo planar imaging, only part of the dead space is measured, which we ignore in these results. Dead space in infancy has been measured by various groups, and estimates range from $1 \cdot 1-2 \cdot 77 \mathrm{ml} / \mathrm{kg}$. ${ }^{10-13}$

In cases 2-8 the lung volumes on echo planar imaging were between 2 and $21 \mathrm{ml} / \mathrm{kg}$ greater than the measurements of thoracic gas volume. Only in case 9 was the thoracic gas volume larger than the echo planar imaging estimation of total lung volume. In this patient a different face mask with a dead space of $28 \mathrm{ml}$ (as 
opposed to $55 \mathrm{ml}$ ) was used. When the infant was sedated it was impossible to obtain a complete seal with our standard mask. It is interesting that previous studies have shown that this mask gives measurements of thoracic gas volume up to a third higher than the mask we usually use, with a dead space of $55 \mathrm{ml}$. Whether the difference is the result of using the small face mask, or of some other effect, remains to be determined.

The right lung was of greater volume than the left lung in all cases except case 2, in whom the left lung was $39 \mathrm{ml}$ larger. Echo planar imaging showed collapse and consolidation in the right lung, which was responsible for the reduced right lung volume. Omitting this patient's results, the mean right lung volumes of the group were between $50 \%$ and $62 \%$ of the total lung volumes. This finding is similar to the results of weighing normal lungs at necropsy. Emery and Mithal found the right lung weighed between $52-57 \%$ of the total lung weight in babies between the ages of 1-12 months. ${ }^{14}$ Cases 8 and 9 had mild wheeze at the time of the study, and were clinically hyperinflated. Their lung volume estimates agree with the clinical assessment (table 2). The use of this method to study individual lung volumes will be of great interest in monitoring lung growth in infants with hypoplastic lungs and after repair of diaphragmatic hernias, ${ }^{15}$ as well as in measuring the effects of scoliosis on lung volume, and in many other conditions.

The images obtained from the more hyperinflated babies seemed less dense that those from the other infants. With improvements in image quality it will be possible to measure the density of the lungs from the echo planar images. Studies are being conducted in older subjects to equate the density reading with actual tissue volume.

We thank the British Heart Foundation, the Medical Research Council, and the Department of Health and Social Security for their support of the echo planar imaging programme.

1 Chrispin A, Small P, Rutter N, et al. Transectional echoplanar imaging of the heart in cyanotic congenital heart disease. Pediatr Radiol 1986;16:293-6. 2 Mansfield P. Multi-planar image formation using NMR spin 1977;10:L55.

3 Mansfield $\mathbf{P}$, Morris PG. Echo-planar imaging. In: Waugh JS, ed. NMR imaging in biomedicine. New York: Academic Press, 1982:143-54.

4 Godfrey S, Beardsmore CS, Maayan C, Barryshay E. Can thoracic gas volume be measured in infants with airways thoracic gas volume be measured in infants with airw
obstruction? Am Rev Respir Dis 1986;133:245-51.

5 O'Callaghan C, Small P, Chapman B, et al. Determination of individual and total lung volumes using nuclear magnetic resonance echo-planar imaging. Ann Radiol 1987;30:470-2.

6 Dubois AB, Botelho SY, Bedell GN, Marshall R, Comroe JH. A rapid plethysmographic method for measuring thoracic gas volume: a comparison with nitrogen washout method for functional residual capacity in normal subjects. $\mathcal{F}$ Clin Invest 1956:35:322-6.

7 Radford M. Measurement of airways resistance and thoracic gas volume in infancy. Arch Dis Child 1974;49:611-5.

8 Stocks J, Levy NM, Godfrey S. A new apparatus for accurate measurement of airways

9 Denison DM, Morgan MDL, Millar AB. Estimation of regional gas and tissue volumes of the lung in supine man using computerised tomography. Thorax 1986;41:620-8.

10 Strang CB. Alveolar gas and anatomical dead space measurements in normal newborn infants. Clin Sci 1961;21:107-14.

ments in normal newborn infants. Clin Sci 1961;21:107-14.
11 Koch G. Alveolar ventilation, diffusing capacity and the $\mathrm{A}-\mathrm{aPO}$
$\mathrm{O}_{2}$
difference in the newborn infant. Respir Physiol $\mathrm{A}-\mathrm{aPO}$
$1968 ; 4: 168-92$.

12 Nelson NM, Prod'hom LS, Cherry RB, Lipszitz PS, Smith CA. Pulmonary function in the newborn infant. I: Ventilation and gaseous metabolism. Pediatrics 1962;30:963-74

13 Lagneaux D, Massey C, Guebelle F, Christiaens G. Alveolar data in healthy, awake neonates during spontaneous ventilation. Pediatric Pulmonol 1988;5:225-33.

14 Emery J, Mithal A. The weight of the lungs. In: Emery J, ed. The anatomy of the developing lung. London: Heinmann Medical, 1969:203-5.

15 O'Callaghan C, Chapman B, Coxon R, et al. Evaluation of infants by echo planar imaging after repair of diaphragmatic hernia. Arch Dis Child 1988;63:186-9. 